This is another fiction masquerading as fact. Szasz is not an ally of National Health Service psychiatrists, none of whom, to my knowledge, has denounced or renounced the practice of psychiatric slavery. Moreover, Szasz is a classical liberal, not a socialist. The two cardinal principles of the classical liberal credo are the affirmation of the right to bodily and mental selfownership and the prohibition against initiating violence.

These rather serious misrepresentations aside, Persaud ignores the core ideas in Szasz's book. Institutional psychiatry is an extension of law: institutional psychiatrists are agents of the state, not of their patients. Doctors who practise contractual medicine are agents of their patients, not of the state. The importance of this difference cannot be overemphasised.

People labelled by institutional psychiatrists as mentally ill are concurrently defined by the courts as less than human, in much the same way 'Negroes' in America were once defined as three-fifths persons. This is how Black people were, and people with mental illnesses are, deprived of liberty and justice by the state. Labelling of anyone as less than human is legal fiction, something false that is asserted as true, that the courts will not allow to be disproved. Just as defining Negroes as three-fifths persons served to maintain the institution of slavery, defining people as mentally ill serves to maintain the institution of psychiatry.

A person has a right to refuse treatment for cancer. A person does not have a right to refuse treatment for mental illness. If institutional psychiatrists are deprived of their power by the state to deprive mentally ill persons of their liberty, that is, if the state did not allow psychiatrists to enslave their patients in the name of liberating them, institutional psychiatry would go the way of slavery, as well it should.

Persaud, R. (2003) Book review: Liberation by Oppression (T. Szasz). British Journal of Psychiatry, 182, 273.

J. A. Schaler Department of Justice, Law and Society, School of Public Affairs, American University, Ward Circle Building, 4400 Mass. Ave. NW,Washington, DC 20016-8043, USA

\section{Treatment of common mental disorders in general practice: are current guidelines useless?}

The paper by Croudace et al (2003) confirms the pattern set by previous studies
(Upton et al, 1999; King et al, 2002) in showing little or no effect of educational and treatment initiatives on primary care physicians' practice of psychiatry. The authors provide various explanations for the negative outcome; one of these 'failures in the content of the guidelines themselves in terms of their evidence base or relevance'-deserves greater prominence. Although psychiatry can claim some credit for advances in the diagnoses and treatment of more-severe disorders seen in secondary care, our interventions for the common mental disorders in primary care are much less securely founded.

The guidelines do not take proper account of the well-established fact that approximately two out of five patients presenting with common mental illnesses in general practice (even when considered ill enough to merit psychiatric input) improve rapidly within a few weeks. These probably merit the often forgotten diagnosis of adjustment disorder (Casey et al, 2001). Thirty per cent pursue a slower course of recovery and a further $30 \%$, mostly with mixed anxiety and depressive disorder, have a worse outcome with frequent relapses (Tyrer et al, 2003), although in the short term a variety of interventions can be effective.

The methodology of Croudace $e t$ al's study is to be commended and the results show that even when guidelines lead to greater specificity in identifying illness, this is not accompanied by better outcomes. Pressured general practitioners in the past used to take the approach that if a patient with mental health symptoms presented for treatment, the doctor could listen sympathetically and, unless there was significant risk, would ask them to come back in 4 weeks' time. If the patient returned, he or she might have a more serious problem necessitating formal treatment. Such an approach may have a greater evidence base than any of our guidelines. It nicely separates those with adjustment disorders from the rest, prevents inappropriate therapies that might lead to iatrogenic problems like dependence, and is an excellent predictor of improvement many years later (Seivewright et al, 1998). If we were able to help general practitioners at the time of presentation to diagnose which patients needed intervention and which did not, we might be doing a better service than any of the current guidelines that litter general practice surgeries in this and many other countries.
Casey, P., Dowrick, C. \& Wilkinson, G. (200I) Adjustment disorders: fault line in the psychiatric glossary. British Journal of Psychiatry, 179, 479-48I.

Croudace, T., Evans, J., Harrison, G., et al (2003) Impact of the ICD-10 Primary Health Care (PHC) diagnostic and management guidelines for mental disorders on detection and outcome in primary care. Cluster randomised controlled trial. British Journal of Psychiatry, I82, 20-30.

King, M., Davidson, O., Taylor, F., et al (2002)

Effectiveness of teaching general practitioners skills in brief cognitive behaviour therapy to treat patients with depression: randomised controlled trial. BM/, 324 947-951.

Seivewright, H., Tyrer, P. \& Johnson, T. (1998)

Prediction of outcome in neurotic disorder: a five year prospective study. Psychological Medicine, 28, II49-II57.

Tyrer, P., Seivewright, H. \& Johnson, T. (2003) The core elements of neurosis: mixed anxiety-depression (cothymia) and personality disorder. Journal of Personality Disorders, in press.

Upton, M. W., Evans, M., Goldberg, D. P., et al (1999) Evaluation of ICD-10 PHC mental health guidelines in detecting and managing depression within primary care. British Journal of Psychiatry, 175, 476-482

\section{Note}

This letter was submitted before the appointment of P.T. as Editor of the Journal.

P. Tyrer, M. King MRC Collaborative Group for the Evaluation of Complex Mental Health Interventions in Primary and Secondary Care, Imperial College and Royal Free Campus of Royal Free and University College Medical School, Rowland Hill Street, London NW3 2PF, UK

J. Fluxman General Practitioner, Harrow Road Medical Centre, London, UK

\section{Management of borderline personality disorder}

Verheul et al's article (2003) states that dialectical behaviour therapy is an efficacious treatment for high-risk behaviours in patients with borderline personality disorder and suggests that this occurs via four core features (Linehan, 1993): routine monitoring; modification of high-risk behaviours; encouragement of patients to consult therapists before carrying out these behaviours; and prevention of therapist burnout.

We propose a management strategy for these patients delivered via a systemic approach that incorporates these principles and is especially relevant for services without the capacity to provide the skills base or intensity required for effective dialectical behaviour therapy. Such an approach has been developed by our service and is currently the principal method of 
working with clients with borderline personality disorder in the lower North Island of New Zealand. It is a servicewide intervention with a long-term perspective, providing stabilisation and containment for both patient and staff. It is encapsulated in a management plan - a behavioural intervention to minimise reinforcement of hazardous behaviours and promote self-responsibility.

The plan defines the treatment system (e.g. psychiatric team, family, police, accident and emergency department staff), contains an acceptance of risk and explains the dangers of risk-averse responses from the service (Maltsberger, 1994). This breaks the cycle of assuming responsibility for the client and replaying a traumatising parent-child dynamic, with subsequent regression, increased risk and institutionalisation. We found that this is achieved through the process of writing and implementing the plan and it enables patients to move towards autonomous functioning. It must be agreed to by all involved and regular review meetings provide a forum for staff to own and manage their differences. Each plan should be an individualised document written by the case manager in consultation with the client; however, we have designed a template for ease of use. This work grew from the ideas of Krawitz \& Watson (1999) around the use of brief admissions as a successful part of long-term management, and the observation that the majority of work by outof-hours services involved these 'revolving door' patients. As yet, our approach has been validated only by empirical evidence. A paper is currently in preparation.

Krawitz, R. \& Watson, C. (1999) Borderline Personality Disorder: Pathways to Effective Service Delivery and Clinical Treatment Options. Wellington: Mental Health Commission of New Zealand.

Linehan, M. (1993) Cognitive Behavioural Treatment of Borderline Personality Disorder. New York: Guilford Press.

Maltsberger, J.T. (1994) Calculated risk taking in the treatment of intractably suicidal patients. Psychiatry, 57, 199-212.

Verheul, R., van den Bosch, L. M. C., Koeter, M.W. J., et al (2003) Dialectical behaviour therapy for women with borderline personality disorder. 12-month, randomised clinical trial in The Netherlands. British Journal of Psychiatry, 182, 135-140.

T. Flewett, P. Bradley, A. Redvers Personality Psychotherapy Service, PO Box 1729, Wellington, New Zealand

\section{Cognitive analytic therapy}

The review by Marks (2003) of our book Introducing Cognitive Analytic Therapy: Principles and Practice (Ryle \& Kerr, 2002) is both rude and misleading. His reminiscences about a visit to Leningrad in 1966 have nothing to do with the book and we certainly do not see 'Pavlovian therapy' (with which we are entirely unfamiliar) as 'part of cognitive analytic therapy (CAT)'. His objection to the fact that our explicitly integrative model draws on a wide range of sources tells us more about the limitations of his own conceptual framework than about CAT. These limitations are also evident in his inability to understand or unwillingness to mention the key features of CAT, which he seriously misrepresents. These include: (a) focus on 'reciprocal role procedures', which are formed though the internalisation of socially meaningful, intersubjective experience and subsequently determine both interpersonal behaviours and selfmanagement; and (b) the practical emphasis on the joint creation of descriptions of these, which serve to enlarge patients' capacity for self-reflection and change and therapists' ability to provide reparative, non-collusive relationships.

The reviewer's bias is epitomised in his discussion of one of the case histories in the book (pp. 138-144). While asserting that this 'patient with obsessive-compulsive rituals' would have been better served by nine sessions of behavioural therapy or by one session plus computer-aided therapy, he fails to record that the patient was presented precisely to illustrate the limitations of cognitive-behavioural approaches and does not mention that she had previously dropped out of an anxiety-management group and of cognitive-behavioural treatment. Of this she had noted that the more her symptoms were worked on, the 'more grimly' she hung onto them. This was not a report of the treatment of obsessivecompulsive rituals, it was a summary of the psychotherapy of a person, an unhappy woman with a history of many years of panic, phobias, obsessive-compulsive behaviours and irritable bowel syndrome. The case was chosen, in part, to demonstrate how focus on presenting symptoms can actually be counterproductive and paradoxically collude with the enactment of underlying reciprocal role procedures in a patient who had come to be regarded as 'difficult' and 'resistant'. This patient's list of 'target problem procedures', as worked out with her, included a pervasive need to control both her feelings and other people's behaviours. As is usual in CAT, this formulation, and her therapy, focused on intra- and interpersonal attitudes, assumptions and behaviours (procedures) and paid little direct attention to her symptoms. Therapy included, importantly, work on reciprocal enactments with the therapist. Assessment at termination and follow-up showed major improvements in her life, and psychometric testing demonstrated reductions in symptoms at termination with further reductions at 6-month follow-up.

We think it unfortunate that so obviously partisan a reviewer was selected to discuss a book outside his area of expertise and sympathy and that it was considered appropriate to publish so tendentious a review of the work of colleagues.

Marks, I. (2003) Book Review: Introducing Cognitive Analytic Therapy (A. Ryle \& I. B. Kerr). British Journal of Psychiatry, 182, 179-180.

Ryle, A. \& Kerr, I. B. (2002) Introducing Cognitive Analytic Therapy: Principles and Practice. Chichester: John Wiley \& Sons.

A. Ryle CPTS, Munro Centre, Guy's Hospital London SEI 9RT, UK

I. B. Kerr Community Health Sheffield NHS Trust, Limbrick Centre, Sheffield, UK

\section{Cinders, you shall go to the ball}

Goodwin has described bipolar disorder as the Cinderella of psychiatry, largely on the basis of his study showing the relative paucity of research studies in bipolar disorder compared with schizophrenia (Goodwin, 2000). This study has been reinforced by Clement et al (2003), who similarly concluded that bipolar disorder is underrepresented compared with schizophrenia and that this disparity is not declining over time. The importance of this discrepancy is demonstrated by the finding that bipolar disorder causes a greater global burden of disease than schizophrenia (Murray \& Lopez, 1997) and by the huge financial impact of bipolar disorder on society (Das Gupta \& Guest, 2002)

Clement and colleagues appear to lay the responsibility for the relative lack of bipolar research on a national shortage of specialist clinical services and on the lack of interest of researchers. However, clinical services such as our own in the Northern Deanery are flourishing and we suggest that historical difficulties in obtaining public 